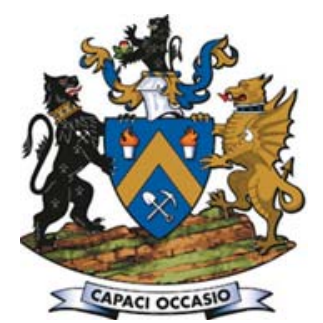

\title{
High-temperature thermal plasma treatment of monazite followed by aqueous digestion
}

\author{
by D. Kemp* and A.C. Cilliers*
}

\section{Synopsis}

Monazite is a chemically inert, radioactive phosphate mineral that contains the light rare earth metals (Ce, $\mathrm{La}, \mathrm{Nd}, \mathrm{Pr}$ and $\mathrm{Y}$ ), thorium and uranium. A new process, which improves the extraction efficiency of monazite, is under development. The equilibrium mole composition, in conjunction with the Gibbs free energy, indicates that as monazite is heated in the presence of carbon to a temperature above $1400^{\circ} \mathrm{C}$, it decomposes into the rare earth oxides. These temperatures are within the operational limits of a thermal plasma. When monazite is fed to a DC plasma it forms amorphous plasma-treated monazite (PTM), which is more susceptible to chemical attack. This increased chemical reactivity permits dilute mineral acids to digest the PTM, which leads to higher extraction efficiencies of the rare earth elements than when monazite is digested using the conventional processes. When the conventional process for digestion of monazite is adapted to PTM, the extraction of rare earth elements, thorium and uranium is increased significantly.

\section{Keywords}

monazite, rare earth elements, thermal plasma.

\section{Introduction}

South Africa is a resource-based economy with an estimated in situ mineral wealth of US $\$ 2.5$ trillion. This makes South Africa one of the wealthiest mining jurisdictions in the world. However, considerable amounts of South Africa's minerals are exported as raw or partially processed ore. South Africa has embraced a mineral beneficiation strategy to develop the value chain for various minerals. One such mineral is monazite (South Africa, 2011) which, until now, underwent minimal industrial beneficiation in South Africa (Kemp and Cilliers, 2014).

Monazite is a chemically inert, radioactive phosphate mineral and is considered to be one of the most important rare earth minerals in the world (Hassan et al., 1997; Amaral and Morais, 2010; Dill et al., 2012). Monazite is a component of 'black sand' found in various beach deposits worldwide (Dilorio et al., 2012) in combination with varying concentrations of ilmenite, magnetite, zircon, rutile and garnet (Ashry et al., 1995; Sroor, 2003). Monazite contains the light rare earth elements (LREE) $\mathrm{Ce}, \mathrm{La}, \mathrm{Pr}, \mathrm{Nd}$ and $\mathrm{Y}$, which are in high demand and the radioactive elements thorium and uranium (Kim et al., 2009). Conventional monazite processing is a complicated, laborious and expensive process (Hurst, 2010) that utilizes highly corrosive media like concentrated sulphuric acid or sodium hydroxide, at elevated temperatures for extended periods of time (Zhu et al., 2015). This process produces large volumes of radioactive and acidic effluents (Xie et al., 2014). For these reasons, China, which produces $97 \%$ of the world's rare earth elements (Hurst, 2010), has prohibited the exploitation of monazite deposits (Zhu et al., 2015). This opens the market for new and innovative technologies for the processing of monazite

Zircon $\left(\mathrm{ZrSiO}_{4}\right)$ is a mineral with a chemically inert crystal structure, which requires harsh alkaline treatment to extract the zirconium metal (Biswas et al., 2010). To overcome the chemical inertness of zircon sand, the South African Nuclear Energy Corporation SOC Ltd (Necsa) has developed a process using a DC non-transferred plasma to convert zircon into plasma-dissociated zircon $\left(\mathrm{PDZ}-\mathrm{ZrO}_{2} \cdot \mathrm{SiO}_{2}\right)$. $\mathrm{PDZ}$ is chemically more reactive than zircon and can be processed more efficiently (Havenga and Nel, 2012; Rendtorff et al., 2012). The high temperatures $\left(10000^{\circ} \mathrm{C}\right)$, good thermal conductivities and high heat contents of thermal plasmas make them ideal for the processing of materials like zircon (Toumanov, 2003; Rendtorff et al., 2012). It is hypothesized that a similar process could increase the chemical reactivity of monazite in order to improve downstream processing efficiency. This would increase the output of the REE, thorium and uranium while simultaneously permitting the use of less aggressive chemical processes (Toumanov, 2003).

* North-West University, Potchefstroom Campus, Potchefstroom, South Africa.

(c) The Southern African Institute of Mining and Metallurgy, 2016. ISSN 2225-6253. This paper was first presented at the AMI Ferrous and Base Metals Development Network Conference 2016 19-21 October 2016, Southern Sun Elangeni Maharani, KwaZulu-Natal, South Africa. 


\section{High-temperature thermal plasma treatment of monazite}

If plasma-treated monazite (PTM) can be processed using less harsh chemicals, as hypothesized, it would create a unique competitive advantage for future rare earth and thorium developers. The new process reduces the environmental and radioactive hazards of monazite processing by treating monazite in a high-temperature thermal plasma followed by low-temperature mineral acid leaching. This paper provides a summary of the current development of this process.

\section{Experimental procedure}

Thermodynamic data from HSC version 6.1, developed by Outotec, was used to evaluate the Gibbs free energy, the equilibrium composition of the dissociation of monazite and to present alternative chemical processes that could require further investigation, or need to be avoided. Monazite is represented as the rare earth (RE) phosphate (REPO4, with $\mathrm{RE}=\mathrm{Ce}, \mathrm{La}, \mathrm{Pr}, \mathrm{Nd}$ and $\mathrm{Y}$ ).

We treated monazite in a DC direct arc plasma batch reactor with the monazite housed in a graphite crucible. The reactor produces a high-temperature electric arc which is used to treat the monazite and produce PTM. The PTM product was heated in a high-temperature oven at $650^{\circ} \mathrm{C}$ for 24 hours to drive off excess graphite formed during the plasma processing.

Crushed monazite $(\mathrm{Mzc})$ was produced by hand-crushing $10 \mathrm{~g}$ of monazite for 10 minutes. Heat-treated monazite (HTM) was produced by heating $20 \mathrm{~g}$ of monazite in an alumina crucible at $1000^{\circ} \mathrm{C}$ for 3 hours, then rapidly cooling the product with water. Inductive monazite (IMz) was produced by heating $20 \mathrm{~g}$ of monazite in a graphite vessel to $1800^{\circ} \mathrm{C}$ in an induction oven. The product was cooled naturally and removed.

Monazite and PTM were leached with various commercially available mineral acids $\left(32 \% \mathrm{HCl}, 65 \% \mathrm{HNO}_{3}\right.$ and $10 \%$ $\mathrm{H}_{2} \mathrm{SO}_{4}$ ) at $80^{\circ} \mathrm{C}$ for 1 hour; concentrated $\mathrm{H}_{2} \mathrm{SO}_{4}$ at $230^{\circ} \mathrm{C}$ for 4 hours, or by alkaline leaching $(60 \% \mathrm{NaOH})$ at $140^{\circ} \mathrm{C}$ for 3 hours followed by mineral acid digestion $\left(\mathrm{HCl}\right.$ or $\left.\mathrm{HNO}_{3}\right)$ at $80^{\circ} \mathrm{C}$ for 1 hour. The concentrations of the individual REE in the leachate samples were determined by ICP analysis at an external laboratory. These values were used to calculate the extraction efficiency of the process.

\section{Results and discussion}

\section{Theoretical decomposition of monazite}

In order to evaluate whether monazite (rare earth phosphates) would dissociate in a plasma, its physical properties were compared to values from the literature and theoretical simulations for a known mineral, zircon $\left(\mathrm{ZrSiO}_{4}\right)$. Monazite has a physically weaker crystal lattice than zircon due to its lower chemical bond strength (Cottrell, 1958) and melting point (Table I) (Pirkle and Podmeyer, 1988; Hikichi and Nomura, 1987). From a physical strength perspective, the monazite crystal is weaker and could be destroyed more easily using less energy than required for zircon. As the plasma can destroy the zircon crystal lattice, (Kock et al., 2011; Havenga and Nel, 2012) it is probable that the monazite crystal could be destroyed in a similar manner.
The temperature at which monazite dissociates without the use of a reagent is unknown at present. Monazite in the presence of excess carbon dissociates into the rare earth oxide, phosphor and carbon monoxide at a temperature between 1200 and $1400^{\circ} \mathrm{C}$ (Equation [1]) (Peng-fei et al., 2010). According to the literature, zircon dissociates into PDZ at $1673 \pm 10^{\circ} \mathrm{C}$. The dissociation temperature can be lowered by $250^{\circ} \mathrm{C}$ when excess carbon is added in the presence of oxygen (Kaiser et al., 2008; Telle, n.d.; Yugeswaran et al., 2015).

$$
2 \mathrm{REPO}_{4}+5 \mathrm{C} \rightarrow \mathrm{RE}_{2} \mathrm{O}_{3}+\mathrm{P}_{2}(\mathrm{~g})+\mathrm{CO}(\mathrm{g})
$$

It is anticipated that the presence of carbon in the plasma could have a similar effect on monazite, which would lower its dissociation temperature by a few hundred degrees Celsius. To determine the potential dissociation temperature of monazite, the Gibbs free energy was used to estimate the temperature at which the individual rare earth $(\mathrm{RE}=\mathrm{Ce}, \mathrm{La}$, $\mathrm{Nd}, \mathrm{Pr}$ and $\mathrm{Y}$ ) phosphates dissociate into the rare earth oxides and a phosphor-oxygen complex.

The dissociation temperature of zircon without excess carbon was accurately plotted using the Gibbs free energy at $1600-1700^{\circ} \mathrm{C}$. Similarly, the Gibbs free energy of the dissociation of monazite in the presence of excess carbon was plotted for a dissociation temperature between 1100 and $1300^{\circ} \mathrm{C}$. The Gibbs free energy of the dissociation of the rare earth phosphates (Equation [2]) indicates that $\mathrm{CePO}_{4}$ dissociates at $1700^{\circ} \mathrm{C}$, as predicted. However the remaining rare earth phosphates dissociate between 2500 and $3000^{\circ} \mathrm{C}$ (Figure 1), which is beyond the anticipated temperature range compared to zircon and $\mathrm{CePO}_{4}$. This dissociation will be investigated further.

$$
2 \mathrm{REPO}_{4} \rightarrow \mathrm{RE}_{2} \mathrm{O}_{3}+\mathrm{PO}_{2}(\mathrm{~g})+\mathrm{O}(\mathrm{g})
$$

\section{Table I \\ Physical properties of monazite and zircon in relation to crystal strength}

\begin{tabular}{|c|c|c|c|c|}
\hline & \multicolumn{2}{|c|}{ Zircon } & \multicolumn{2}{c|}{ Monazite } \\
\hline \multirow{2}{*}{ Melting point $\left({ }^{\circ} \mathrm{C}\right)$} & \multicolumn{2}{|c|}{$2100-2300$} & \multicolumn{2}{|c|}{2057} \\
Chemical bond strength $(\mathrm{kJ} / \mathrm{mol})$ & $\mathrm{Si}-\mathrm{O}:$ & 798 & $\mathrm{P}-\mathrm{O}:$ & 596 \\
& $\mathrm{Zr}-\mathrm{O}:$ & 760 & $\mathrm{RE}-\mathrm{O}:(\mathrm{av})$. & 753 \\
\hline
\end{tabular}

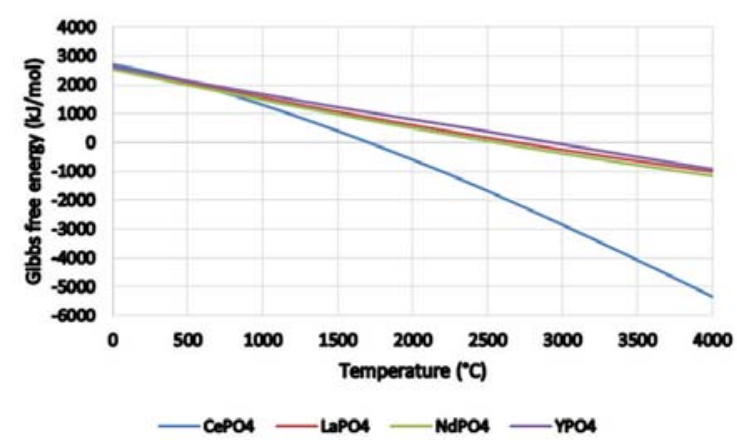

Figure 1-Gibbs free energy of the dissociation of monazite (rare earth phosphate) into the rare earth oxides and phosphor dioxide 


\section{High-temperature thermal plasma treatment of monazite}

The formation of the rare earth oxides from monazite would improve the leachability of the plasma-treated monazite (PTM). This is because the highly inert monazite crystal would have been destroyed enabling the rare earth oxides to be leached using a diluted mineral acid, unlike the rare earth phosphates (Peelman et al., 2014).

\section{Plasma treatment of monazite}

The starting material for all plasma cycles was monazite sand obtained from an external source. The sand consisted of $69.55 \%$ monazite, $17.67 \%$ zircon and $4.85 \%$ ilmenite with the remaining $7.93 \%$ consisting of other materials. Examination of the monazite sand by optical microscopy revealed a number of oval-shaped brown, red, white and black particles (Figure 2). These oval-shaped particles are reminiscent of this monazite sample and may differ from other monazite samples.

$\mathrm{X}$-ray diffraction (XRD) analysis of monazite sand (Figure 3) and PTM was used to determine whether plasma treatment induces any structural or compositional changes in monazite. The XRD pattern of this monazite (Figure 3) shows peaks at $2 \theta=26.5^{\circ}, 28^{\circ}, 35^{\circ}$ and $47^{\circ}$, along with a number of smaller peaks. The peak at $2 \theta=26.5^{\circ}$ was positively identified as that of the rare earth phosphates,

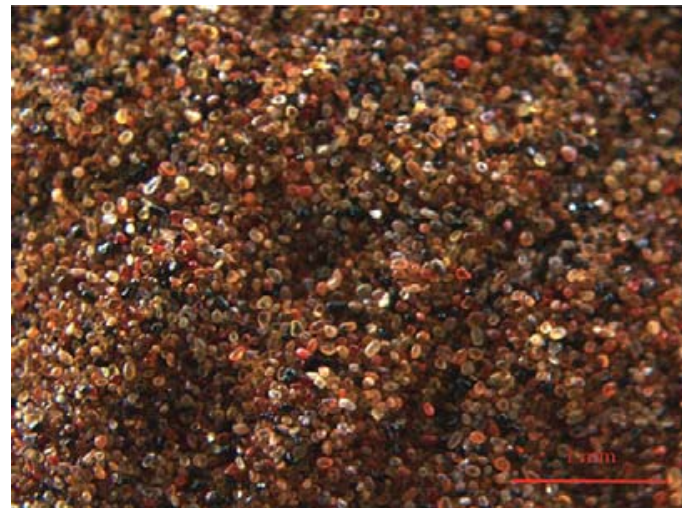

Figure 2-Optical micrograph of monazite which are components of monazite. No further analysis for this study was completed.

We produced PTM by placing monazite sand in a graphite crucible and treating it in a DC direct arc plasma. We removed the PTM graphite layer after plasma treatment by heating the PTM in a conventional oven at $650^{\circ} \mathrm{C}$ for 24 hours, producing plasma-treated monazite heated (PTMH). We found that when monazite is treated incorrectly it behaves and looks like monazite when viewed under an optical microscope and analysed using XRD. If monazite is heated in the plasma for too long it melts and forms larger, more inert monazite particles. When monazite is treated correctly in the plasma then the changes to the physical structure of the particles are visible under an optical microscope, as all of the oval-shaped particles are destroyed (Figure 4). For this reason, it can be concluded that the proper treatment of monazite can be verified partially through the use of an optical microscope. Elemental X-ray fluorescence analysis on all PTM samples indicated no statistical difference in the elemental composition compared with the original monazite.

XRD analysis of PTMH confirmed the destruction of the monazite crystal structure. The absence of the monazite peaks (Figure 5) indicates that a completely amorphous powder has been produced. This indicates that the inert

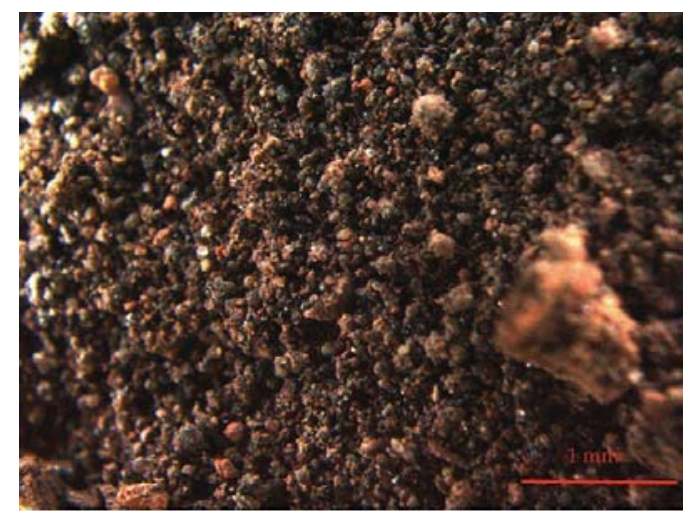

Figure 4-Optical micrograph of plasma-treated monazite

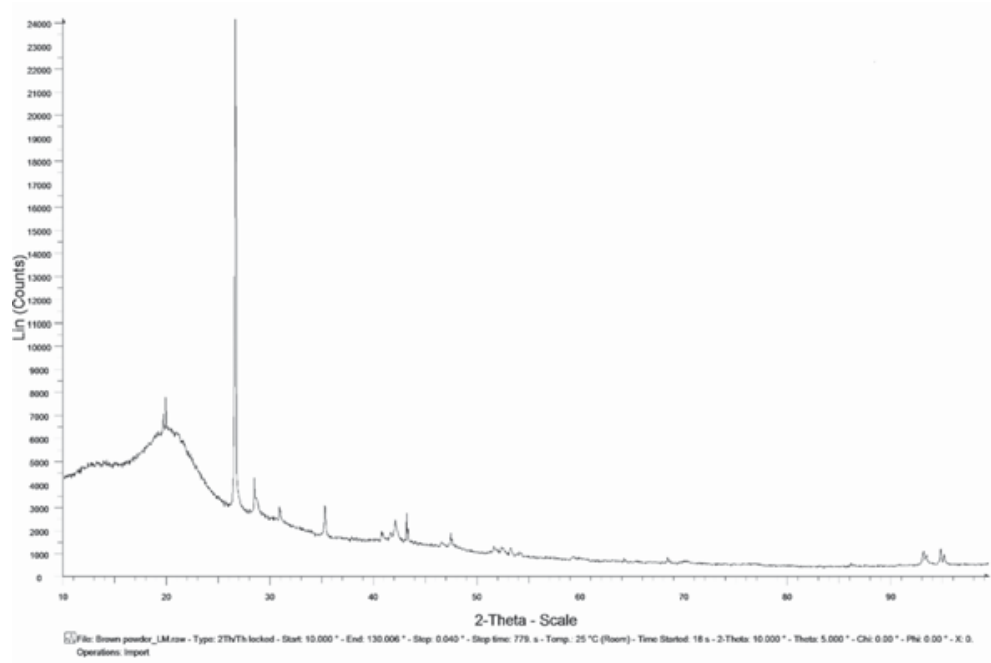




\section{High-temperature thermal plasma treatment of monazite}

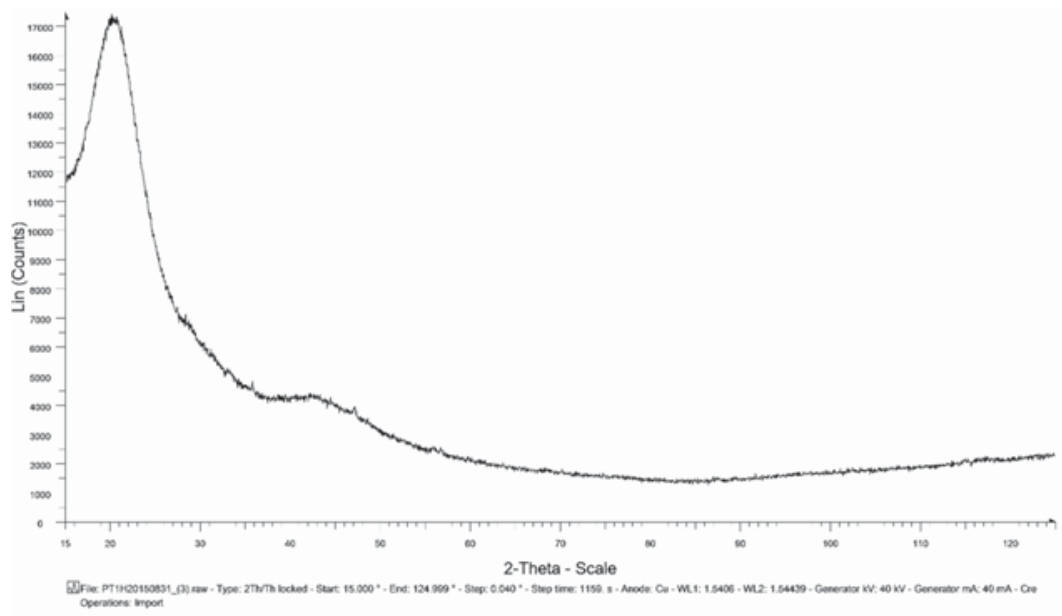

Figure 5-XRD pattern of amorphous plasma-treated monazite

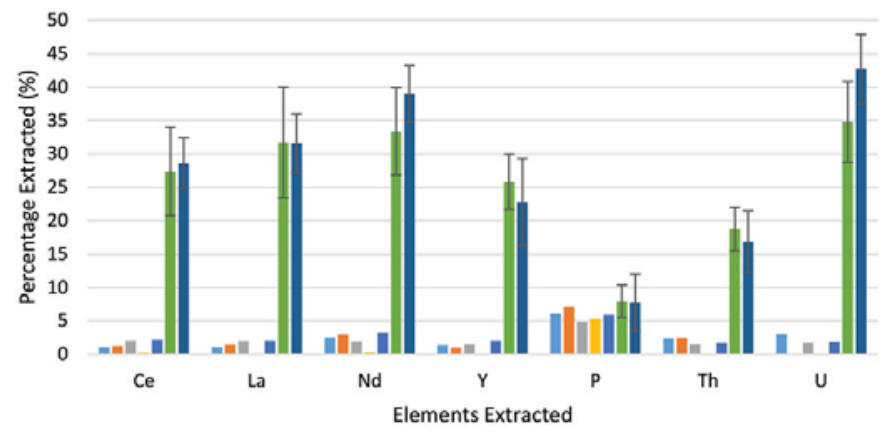

Figure 6-Extraction efficiency from various forms of monazite using $32 \% \mathrm{HCl}$ at $80^{\circ} \mathrm{C}$ for 1 hour

phosphate crystal matrix, which is responsible for the inert nature of monazite (El-Nadi et al., 2005), has been destroyed. The disadvantage of the formation of the amorphous substance is that the presence of the more reactive rare earth oxides cannot be confirmed. Other minerals, like zircon, have also been destroyed.

\section{Chemical reactivity of plasma-treated monazite}

In order to confirm the hypothesis that the plasma treatment of monazite delivers a more reactive product, PTM and PTMH were digested using a variety of different lixiviants multiple times. The results indicate the quantity of the specific element extracted, as a percentage of the original amount of that element in the starting material. The standard deviation is shown as error bars. In order to obtain a proper comparison of the reactivity, additional samples were tested, like monazite (Mz), crushed monazite (Mzc), heat-treated monazite (HTM) and inductive monazite (IMz).

Digestion of PTM extracted on average 20 times more of the REE, 7 times more thorium and up to 11 times more uranium compared with untreated samples. Comparison of the extraction efficiency from Mz, Mzc, HTM, IMz, PTM and PTMH with $32 \% \mathrm{HCl}$ (Figure 6) shows that simply heating the monazite (HTM and IMz) in a graphite crucible, even to a temperature above $1800^{\circ} \mathrm{C}$, does not result in a more reactive product. The phosphor content remained reasonably constant throughout and cannot be used as an accurate indicator of the efficiency of the extraction process.
The results demonstrate the importance of using an appropriate temperature and treatment time period in order to increase the chemical reactivity of monazite. The plasma treatment of monazite is the predominant reason for improved REE and thorium extraction, as the plasma treatment destroys the monazite crystal matrix and produces amorphous PTM (Kemp and Cilliers, 2016a). Comparing the REE extraction efficiencies between heat-treated $\left(\mathrm{PTM}_{\mathrm{H}}\right)$ and non-heat-treated PTM reveals a small but significant increase in the extraction efficiency. The multiple experiments conducted for this study were not optimized and the potential advantage gained by removing graphite from PTM requires further investigation.

In order to develop the process, the digestion of monazite and PTMH with various reagents was compared. Each experiment was repeated several times until a satisfactory standard deviation was achieved. These reagent included $65 \% \mathrm{HNO}_{3}\left(\mathrm{HNO}_{3}\right)$ and $10 \% \mathrm{H}_{2} \mathrm{SO}_{4}\left(\mathrm{H}_{2} \mathrm{SO}_{4} \mathrm{~d}\right)$ at $80^{\circ} \mathrm{C}$ for 1 hour, $98 \% \mathrm{H}_{2} \mathrm{SO}_{4}$ at $230^{\circ} \mathrm{C}$ for 4 hours $\left(\mathrm{H}_{2} \mathrm{SO}_{4} \mathrm{C}\right)$ and $60 \%$ $\mathrm{NaOH}$ at $140^{\circ} \mathrm{C}$ for 3 hours followed by either $32 \% \mathrm{HCl}$ $(\mathrm{NaOH} / \mathrm{HCl})$ or $65 \% \mathrm{HNO}_{3}\left(\mathrm{NaOH} / \mathrm{HNO}_{3}\right)$ at $80^{\circ} \mathrm{C}$. The average extraction efficiencies of the various digestion processes over multiple experiments for monazite (Figure 7) and $\mathrm{PTM}_{\mathrm{H}}$ (Figure 8) show clearly that $\mathrm{PTM}_{\mathrm{H}}$ is more reactive than monazite. The optimum REE extraction using aqueous digestion from $\mathrm{PTM}_{\mathrm{H}}$ was obtained using $32 \% \mathrm{HCl}$, which resulted in an average extraction efficiency of $38.44 \%$. Alkaline digestion followed by $\mathrm{HNO}_{3}$ yielded the highest 


\section{High-temperature thermal plasma treatment of monazite}

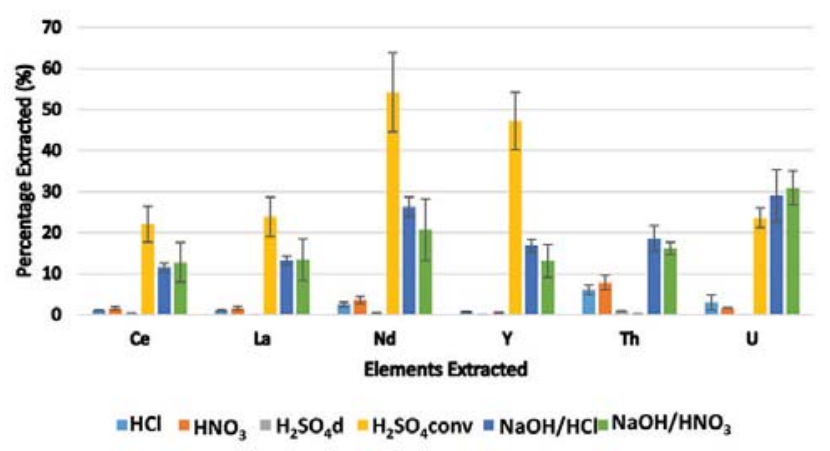

Figure 7-Extraction efficiencies of the rare earths, thorium and uranium from monazite for each reagent

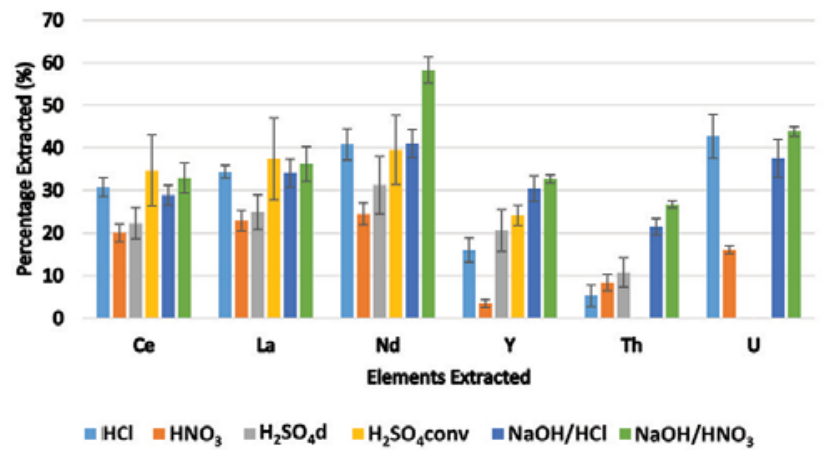

Figure 8-Extraction efficiencies of the rare earths, thorium and uranium from PTM $_{H}$ for each reagent

possible extraction efficiency of $38.56 \%$ for the REE. Digestion using concentrated $\mathrm{H}_{2} \mathrm{SO}_{4}$ did not result in any vast improvement on the process, but did indicate that thorium was not extracted. Phosphor, which is still present in the $\mathrm{PTM}_{\mathrm{H}}$, is a contaminant that reduces the percentage of material extracted from the process (Kemp and Cilliers, 2016b).

The simpler diluted mineral acid digestion delivered higher extraction efficiency values for the REE, thorium and uranium from $\mathrm{PTM}_{\mathrm{H}}$ - within $30 \%$ of those obtained using the conventional process - and has the distinct advantage of being simpler, easier to work with and potentially more economical. The conventional monazite digestion processes is more efficient at extracting the REE from $\mathrm{PTM}_{\mathrm{H}}$ than the diluted mineral acids, with varying degrees of success for thorium and uranium. The extraction values obtained for $\mathrm{Nd}$ and $\mathrm{Y}$ by the conventional $\mathrm{H}_{2} \mathrm{SO}_{4}$ process were consistently high. No explanation can be given at this time and this phenomenon will be investigated further.

Thorium is found in monazite worldwide and can be used as fuel in a nuclear reactor (Greneche et al., 2007). $32 \% \mathrm{HCl}$ extracted $16.89 \%$ of the available thorium from monazite, PTM and $\mathrm{PTM}_{\mathrm{H}}$. The digestion of $\mathrm{PTM}_{\mathrm{H}}$ with $60 \% \mathrm{NaOH}$ followed by $\mathrm{HNO}_{3}$ obtained the highest extraction efficiency for thorium along with the REE. This is surprising, as the thorium should have been at a minimum due to it precipitating out as $\mathrm{Th}(\mathrm{OH})_{4}$. This phenomenon will be investigated further.

To produce PTM the monazite sample must be rapidly heated to allow it to properly dissociate and cooled rapidly to prevent the monazite particles from fusing together to form larger, more inert particles. This can be accomplished with the use of an in-flight RF induction plasma or a DC nontransferred arc plasma, whereby the monazite would be subjected to the required rapid heating rate. After the rapid heating of the monazite particles, the design of the in-flight plasma would allow the particles to cool fast enough to prevent the formation of excessively large particles or recombination as a rare earth phosphate (Boulos, 1985).

\section{Conclusion}

The objective of this study was to treat monazite in a plasma in order to extract the rare earths, thorium and uranium more efficiently. Theoretically. when monazite, as a rare earth phosphate, is treated in a thermal plasma at $1600^{\circ} \mathrm{C}$, it decomposes into chemically more reactive rare earth oxides. XRD analysis of plasma-treated monazite (PTM) indicated that the monazite crystal matrix was destroyed to produce an amorphous substance. It was determined that in order for the monazite to become more reactive the temperature and duration of the plasma treatment are crucial, otherwise, there would only be a minimal increase in chemical reactivity. PTM can be leached using a dilute mineral acid at a lower temperature and in less time, than in the conventional monazite processes, while obtaining similar extraction values. The overall conclusion of the study is that the plasma treatment of monazite increases its chemical reactivity. This knowledge can now be used to develop a more efficient and economical process than the comparable conventional chemical digestion methods currently employed to process monazite. 


\section{High-temperature thermal plasma treatment of monazite}

\section{Acknowledgements}

The authors thank the South African Nuclear Energy Corporation SOC Ltd (Necsa) and the Nuclear Materials Development Network of the Advanced Metals Initiative of the Department of Science and Technology of South Africa for financial support.

\section{References}

AmARAL, J.C.B.S. and MorAIs, C.A. 2010. Thorium and uranium extraction from rare earth elements in monazite sulfuric acid liquor through solvent extraction. Minerals Engineering, vol. 23, no. 6. pp. 498-503.

Ashry, H.A., KHAZBAK, A.E., Soliman, F.A.S. and IBrahim, M.A. 1995. Determination of uranium and thorium content in the various stages of monazite upgrading. Applied Radiation and Isotopes, vol. 46, no. 8. pp. 735-739.

BisWas, R.K., Habib, M.A., KarmaKar, A.K. and IsLam, M.R. 2010. A novel method for processing of Bangladeshi zircon: Part I: Baking and fusion with NaOH. Hydrometallurgy, vol. 103, no. 1-4. pp. 124-129.

Boulos, M.I. 1985. Inductively coupled R.F. (radio frequency) plasma. Pure and Applied Chemistry, vol. 57, no. 9. pp. 1321-1352.

CotTRELl, T.L. 1958. The Strengths of Chemical Bonds. 2nd edn. Butterworth, London.

Dill, H.G., WebER, B. and KLoSA, D. 2012. Morphology and mineral chemistry of monazite-zircon-bearing stream sediments of continental placer deposits (SE Germany): Ore guide and provenance marker. Journal of Geochemical Exploration, vol. 112. pp. 322-346.

Dilorio, C.L., Knight, D.J. and Mancuso, M.P. 2012. Adoption of thorium power. Project Number IQP-BJS-TP11. Worcester Polytechnic Institute, Worcester, MA.

EL-NAdi, Y.A., DAoud, J.A. and Aly, H.F. 2005. Modified leachingt and extraction of uranium from hydrous oxide cake of Egyptian monazite. International Journal of Mineral Processing, vol. 79. pp. 101-110.

Greneche, D., SzymczaK, W.J., Buchheit, J.M., Delpech, M., Vasile, A. and Jolfier, H. 2007. Rethinking the thorium fuel cycle: an industrial point of view. Proceedings of the International Congress on Advances in Nuclear Power Plants, Nice. Paper 7367.

GUPTA, C.K. and KRISHNAmURTHY, N. 2005. Extractive Metallurgy of Rare Earths CRC Press, Boca Raton, FL.

Hassan, A.M., Abdel-Wahab, M., NadA, A., Walley El-Dine, N. and KhazbaK, A. 1997. Determination of uranium and thorium in Egyptian monazite by gamma-ray spectrometry. Applied Radiation and Isotopes, vol. 48, no. 1. pp. 149-152.

HAVENGA, J.L. and NeL, J.T. 2012. The manufacture of plasma- dissociated zircon (PDZ) via a non- transferred arc process utilizing three $150 \mathrm{~kW} \mathrm{DC}$ plasma torches. Journal of the Southern African Institute of Mining and Metallurgy, vol. 112, no. 7. pp. 12-14.

Hiкісні, Y. and NomURA, T. 1987. Melting temperatures of xenotime and monazite. Jounal of the American Ceramic Society, vol. 70, no. 10. pp. C252-C253.

HuRST, C. 2010. China's rare earth elements industry: what can the West learn? Institute for the Analysis of Global Security, Potomac, MD. http://www.iags.org/rareearth0310hurst.pdf

Kaiser, A., LoBert, M. and Telle, R. 2008. Thermal stability of zircon $\left(\mathrm{ZrSiO}_{4}\right)$. Journal of the European Ceramic Society, vol. 28, no. 11. pp. 2199-2211.
KemP, D. and CilLiers, A.C. 2014. Fluorination of rare earth, thorium and uranium oxides and phosphates from monazite a theoretical approach, Proceeding of the 2014 AMI Light Metals Development Network Conference, Pilanesberg, South Africa. pp. 439-445

Kemp, D. and CilLiers, A.C. 2016a. High temperature plasma treatment of monazite. International Journal of Mineral Processing. [Under review].

KeMP, D. and Cilliers, A.C. 2016b. Theoretical and experimental evaluation of the digestion of plasma treated monazite with diluted $\mathrm{HCl}$ and $\mathrm{HNO}_{3}$. International Journal of Mineral Processing. [Under Review].

KIM, W., BAE, I., CHAE, S. and SHIN, H. 2009. Mechanochemical decomposition of monazite to assist the extraction of rare earth elements. Journal of Alloys and Compounds, vol. 486, no. 1-2. pp. 610-614.

Kock, L.D., LeKGoATHI, M.D.S., SNyders, E., WAgener, J.B., Nel, J.T. and HAVENGA, J.L. (2011). The determination ofpercentage dissociation of zircon $\left(\mathrm{ZrSiO}_{4}\right)$ to plasma-dissociated zircon $\left(\mathrm{ZrO}_{2} \cdot \mathrm{SiO}_{2}\right)$ by Ramamn spectroscopy. Journal of Raman Spectroscopy, vol. 43, no. 6. pp. 769-773.

Peelman, S., Sun, Z.H.I., SieTsma, J. and Yang, Y. 2014. Leaching of rare earth elements: Past and present, Proceeding of the ERE2014L 1st European Rare Earth Resources Conference, Milos, Greece, 4-7 September 2014. pp. 446-456

PiRKLE, F.L. and PoDmeYer, D.A. 1988. Zircon: origin and uses. Transactions of the Society for Mining, Metallurgy and Exploration, vol. 292. pp. 1-20.

RendtorfF, N.M., SuÁreZ, G., Conconi, M.S., Singh, S.K. and Aglietti, E.F. (2012). Plasma dissociated zircon (PDZ) processing; influence of the $\mathrm{Zr}: \mathrm{Si}$ ratio in the composition, microstructure and thermal re-crystallization. Procedia Materials Science, vol. 1. pp. 337-342.

Russian Foundation of BASIC RESEARch. 2008. Mincryst. http://database.iem.ac.ru/mincryst/s_lattice.php?ZIRCON [accessed 16 Mar. 2016].

South AFricA. 2011. A beneficiation strategy for the minerals industry of South Africa June 2011. Department of Mineral Resources.

SRoor, A. 2003. Passive and active measurements of Egyptian monazite samples. Applied Radiation and Isotopes, vol. 58, no. 2. pp. 281-285.

TelLe, R. (Not dated) Thermal stability of zircon $\left(\mathrm{ZrSiO}_{4}\right)$ and its dependence on natural impurities in the raw materials. Institut für Gesteinshüttenkunde, RWTH Aachen University.

Toumanov, I.N. 2003. Plasma and High Frequency Processes for Obtaining and Processing Materials in the Nuclear Fuel Cycle. Nova Science Publishers, New York.

Xie, F., An Zhang, T., Dreisinger, D. and Doyle, F. 2014. A critical review on solvent extraction of rare earths from aqueous solutions. Minerals Engineering, vol. 56. pp. 10-28.

XING, P., Zhuang, Y., Tu, G. and Guo, J. 2010. High temperature dephosphorization behavior of monazite concentrate with charred coal. Transactions of Nonferrous Metals Society of China, vol. 6326, December 2009. pp. 2392-2396.

Yugeswaran, S., Ananthapadmanabhan, P.V., Thiyagarajan, T.K. and RAMACHANDRAN, K. 2015. Plasma dissociation of zircon with concurrent inflight removal of silica. Ceramics International, vol. 41, no. 8 . pp. 9585-9592.

Zhu, Z., Pranolo, Y. and Cheng, C.Y. 2015. Separation of uranium and thorium from rare earths for rare earth production - a review. Minerals Engineering, vol. 77. pp. 185-196. 